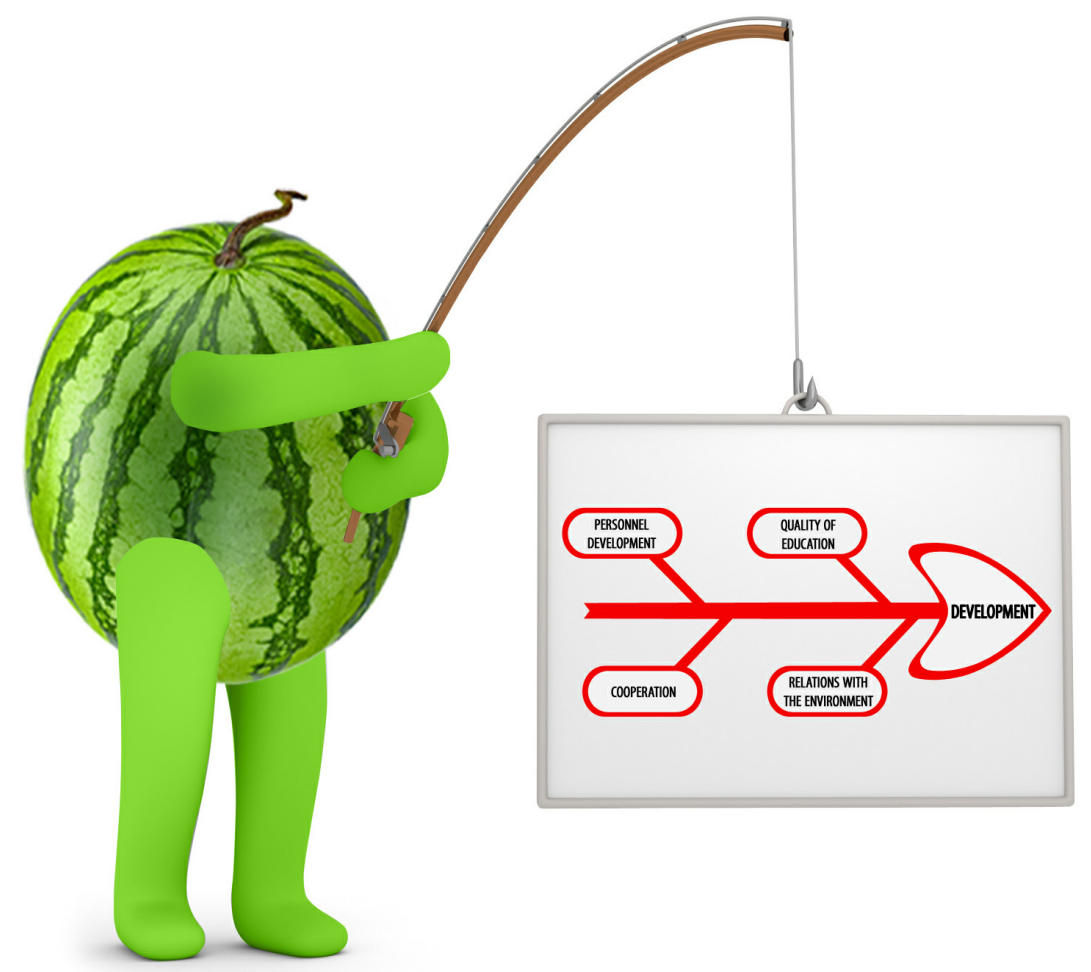

\title{
BUILDING A STRATEGY FOR THE DEVELOPMENT OF A UNIVERSITY USING THE METHODOLOGY OF STRATEGIC SESSIONS ON THE EXAMPLE OF THE ACADEMY OF FINE ARTS IN ŁÓDŹ
}




\section{S sciendo}

\section{BUILDING A STRATEGY FOR THE DEVELOPMENT OF A UNIVERSITY USING THE METHODOLOGY OF STRATEGIC SESSIONS ON THE EXAMPLE OF THE ACADEMY OF FINE ARTS IN ŁÓDŹ}

\section{Piotr Mikosik, PhD}

Warsaw Management University

piotr.mikosik@gmail.com

DOI: 10.2478/minib-2019-0032

\section{Summary}

The aim of the article is to present the methodology of building an organization strategy which the author has been working on for 8 years. Although the article is based on the case study of the Academy of Fine Arts (ASP) in kódź, in which the author conducted a series of strategic sessions, the methodology itself is universal and can be successfully applied both in enterprises, non-profit organizations and offices. The size of the organization or industry is also irrelevant. The author applied the described method in international corporations, no-profit organizations as well as kindergartens whose teams worked on the concept of development of their organizations. The article presents a full process of creating a strategy, however, due to the limit of pages imposed by the publishing house, only selected methods used during strategic sessions are described.

Keywords: methods, methodology, team, strategy, moderated session 



\section{Introduction}

The author familiarized himself with the methods presented in the article 8 years ago. Since then, he has used them a few dozen times during training sessions and strategic sessions. These methods supported management staff both in solving complex organizational problems as well as preparing strategies. Among the participants of these trainings were large enterprises (KGHM, BSS, ORIX, Sheraton, PKO BP), smaller companies, local government units (e.g. Tomaszów Mazowiecki city authorities), educational organisations (psychological counselling centres, high schools, junior high schools) and the W. Strzemiński Academy of Fine Arts in Łódź (ASP). The methods used have also proved useful during classes conducted with students.

The aim of the article is to present the methodology of working with a team on building an organization's development strategy. In order to prepare the conclusions described below, two research methods were used: participatory observation conducted during strategic sessions and case study.

In his research work, the author first of all tried to assess the values and limitations of the methods. In particular, the subject of interest was the evaluation of: a) the adjustment of each method to the problem faced by the team, b) the mutual adjustment of methods to each other, so as to create a coherent and universal methodology and c) the selection of methods to the specificity of the group.

Over the years of conducting research, individual methods have changed little. Some of them were abandoned because they proved to be of little use, as they included too much duplication of schemes existing in other methods or were too complicated for teamwork conditions. Other methods were modified, especially when they contained methodological or logical gaps. The aim of this selection and modification was to try to achieve greater methodological consistency in order to reduce the gaps in the process of situation analysis, design and solution assessment. Finally, from a group of about 70 methods more than 20 were selected, which are the canon of the methodology presented here.

However, the cognitive value of this research does not depend on explaining the methods themselves. Most of them are generally available 
and described in the literature. A special research contribution to the problems of solving organizational problems and creating strategies was to be based on the development of the whole methodology - ordered in a logical and coherent process. The assumption that inspired the author from the very beginning was to develop a universal methodology that can be used in companies and non-profit organizations, in every branch and in work with every team. To a large extent, this assumption was achieved. Of course, this methodology has its limitations. It will not replace the lack of competence of the team. No methodology will work in a situation when the scale of the problem exceeds the level of understanding of those who want to solve it. . The methodology will not be favoured by people who do not accept criticism and do not allow themselves to be aware that they may be wrong. It will also be rejected by autocratic leaders, for whom an open exchange of views, especially with lower-ranking employees, is treated as a display of weakness.

During the strategic sessions at the Academy of Fine Arts in Łódź, the author received permission from the team to describe the course and results of the session. In this article, efforts have been made to present the results of the session in a reliable way, although descriptions of such problems and situations are omitted, the disclosure of which could be considered "inelegant", let alone unethical. In this article, the problems discussed during sessions in ASP are slightly truncated and slightly generalised. Firstly, in order not to overload the reader with details that are unnecessary for understanding the essence of things, secondly, to make the message more transparent also for these readers who do not know the specificity of a high school functioning. This procedure should not have a negative impact on the quality of the interview. What is more, a higher level of generalisation of problems makes the argument more universal and representative of the situation that exists in many other universities in Poland.

\section{Clarification of basic concepts}

Strategy - is an action plan that reflects the management pattern in the market sphere and shows how to fulfill the mission and achieve 
the objectives (Wright P., Pringle D., Kroll J.M., 1992 p. 3). In the author's understanding, a strategy is a concept of actions which is supposed to allow to achieve objectives which have been defined on the basis of a thorough diagnosis of the strategic situation.

Moderated strategic/problem session - is a special kind of managerial training whose aim is to prepare an organization's development strategy or to solve a complex problem. More specifically, in the professional training nomenclature the term "session" is a different concept from "training". During training, the trainer provides information that allows participants to increase the scope of their knowledge. Therefore, training is similar in its form to lectures or exercises conducted in universities. Meanwhile, a strategic or problem session is based on the assumption that participants have the necessary substantive knowledge to go through the process of creating a strategy or solve the problem. However, they do not have knowledge about the methodology of creating strategies or solving problems. Without the help of a moderator, the team could get lost in the intricacies of analytical methods or creative thinking techniques. However, the role of a moderator is not to teach methods. Using his knowledge of methods, the moderator is to lead the team through the process of creating a strategy - from the phase of analysing the situation through defining goals to preparing the concept of the strategy and plans for its implementation. The article describes the methodology of strategic sessions, although the methodology of conducting sessions of solving team problems is similar and based on the same group of methods.

It is worth noting that the term close to the concept of moderation is facilitation. The PWN Dictionary defines facilitation as "the mutual influence of members of a group causing an increase in behavior of a certain kind". (PWN, 2018) In a professional nomenclature, a facilitator is considered to be a person who "clears and directs" the communication process in a team in which this communication fails. The goal of the facilitator, contrary to the goal of the moderator, is not to lead the team to achieve a certain result, e.g. to work out a solution. At present, however, the concepts of moderation and facilitation are used interchangeably and in the "Process Iceberg" methodology, for example, the role of the facilitator is almost identical to the role of the 
moderator described here. On the other hand, e.g. journalists conducting a debate on television are called moderators of the discussion, although their aim is to "clarify and direct" the participants' statements on a given topic.

Method and methodology - these terms are often used interchangeably. According to Schuman, a method is a way of proceeding, leading to the solution of a given problem and the achievement of a defined goal. It consists of defined and repeatable stages (H. Schuman, 2013, p. 25). This definition does not seem to be precise enough, because the concept of methodology can be described in a similar way. For this reason, the following definitions of these concepts are proposed in the article.

A method is a structured scheme of action, e.g. a sequence of steps aimed to achieve a partial goal that is a stage or part of a stage defined by the methodology. An example of a commonly known diagnostic method is a 'SWOT analysis'. which aims to identify the strengths and weaknesses of the organisation and the opportunities and threats on the market. Completion of the SWOT analysis allows to move to the next method, which is the next stage in the methodology of strategy design.

The notion of method is sometimes used interchangeably with the notion of technique. In the literature, "technique" is defined in a similar way to "method", although the difference between the two concepts results from the scale. A technique is usually considered to be of lesser importance and importance than a method. A method with a high degree of detail becomes a technique, a procedure, a prescription. (Z. Martyniak, 1999, p. 7). Due to the fact that it is difficult to determine the boundary between a technique and a method, the article does not distinguish between these concepts and often uses them interchangeably.

Methodology is a set of methods ordered in a logical process.

\section{Specificity of university management}

The article describes the methodology of strategy building using moderated strategic sessions. Although the article is based on the case 
study of the Academy of Fine Arts in Łódź, the methodology itself is universal and can be successfully used to prepare a strategy for a company, office, theatre club or kindergarten.

Although the general structure of a strategy session is similar for each type of organization, the course of the session itself or the internal logic of the methods used will be different. They must be adapted to the unique characteristics of each type of organisation. Therefore, it is worthwhile to introduce a few key aspects of university functioning which determine decisions of strategic nature.

In companies operating in a highly competitive environment, one of the most important departments is the marketing department, and the position of marketing director is considered to be crucial in the organizational structure of companies and having a strong impact on the strategy.

Higher education institutions in Poland operate in the conditions of decreasing demand. The number of secondary school graduates was about 700,000 in 2002, and by 2020 it is expected to decrease to about 350,000, i.e. by $50 \%$ (CSO 2017). Therefore, competitive conditions in the industry have been increasingly difficult for years. The interviews conducted by the author show that in Polish public universities it is difficult to meet a professional marketing department performing a role similar to that existing in business. In public universities there are only promotion departments, dealing with current information activity, whose employees, due to savings, are often recruited from among students. These departments, of course, have no influence on the strategy of the university. In the case of non-public universities, the situation looks slightly better. (Mikosik, 2014).

Universities have a unique, as far as business conditions are concerned, specificity of organizational culture. First of all, there is a strong separation between academic and administrative staff. These environments create different organisational cultures and there is no need to prove that the position and prestige of the scientific community is dominant. This specificity is important for the selection of management staff. An employee performing important managerial functions in a university who would not hold a university degree will not be appreciated by scientists, and their influence on this environment will be limited. 
Relationships within the organisational structure of a university are also specific. The dean of a faculty formally supervises the faculties. At the same time, the dean is also a researcher and a member of the faculty. Therefore, the dean is both the supervisor and subordinate to the head of the department. This structural complexity is difficult for the business community to understand. A similar situation in the company would lead to a decision making process and is treated as normal at universities.

The rector, and in particular a public higher education institutionis is elected from among the staff of the institution. After the end of the term of office, he or she usually becomes an "ordinary" academic employee, and another employee is elected in his or her place. Therefore, if the rector is guided by common sense, he or she must take this fact into account when making difficult, e.g. personal decisions. It is therefore logical that in order to avoid conflicts they will behave conservatively if they do not want to be exposed to possible future consequences. This situation is one of the reasons for the high inertia of universities towards the implementation of changes.

The above mentioned phenomena do not present a full panorama outlining the specificity of functioning and management of a higher education institution. They are presented as examples of the challenges faced by university management and how different these challenges are from those faced by the management of a company. In order to prepare and implement university strategies, these phenomena are of key importance. Without taking into account the limitations that result from them, in the area of making and implementing decisions, it is impossible to prepare an effective strategy.

\section{Strategy development process}

The classic model of strategy building

Before explaining the strategy building process used during moderated strategic sessions, it is worthwhile to refer to the classical model. The most popular model, described in most of the strategic 
management manuals, is based on the following stages (e.g. Kłeczek R., Kowal W., Woźniczka J. 2001 p. 51):

1. Building a vision and mission

2. Analysis of the strategic situation: analysis of the environment, internal analysis, SWOT

3. Setting the strategic objective and strategy

4. Setting objectives and operational programmes

5. Implementation and control.

It is difficult to accuse this model of lack of logical order. It starts with the most general area, i.e. outlining the image of the company's concept (vision) then moves on to strategic diagnosis in order to outline the direction and plan of further action in the next step.

However, this model should be accused of excessive simplification which results in its limited usefulness in the development of the strategy. In his outstanding book, R. Rumelt critically addressed such models accusing them of limited usefulness. He calls this process "building a template-based strategy". It is difficult to promote a critical evaluation of Rumelt's templates since the aim of the article is to present a template for conducting a strategy session. However, one should agree with the author of the book "Good strategy, bad strategy" that starting the process of building a strategy from creating a vision is deceptive because of the risk that this vision will be missed out on the hard reality of the situation.

The author of the article had a chance to see for himself how weak it is to start building a strategy with a vision. In the years 2012-2014 he participated in the programme of school development in the Eódź Province. The aim of the program was, among others, to help create a strategy for the development of these centers. Several of them were in a very difficult situation with poor educational results, falling interest on the part of candidates, an increase in the number of so-called difficult students and a depreciation of the school's prestige.

Initially, work on the strategy began with the creation of an ambitious vision for the future, on the basis of which the ways of its implementation were developed. In several schools, this approach was met with a wave of criticism from participants and was rejected. The criticism stemmed from the realism of their situation, i.e. lack of budget, lack of specialised staff, professional burnout of teachers who did not 
show goodwill to engage in the development of their own workplace, and often the deepening conflict between management and teachers. All these factors led to lack of confidence in any change among the team. In other words, schools were often in the grip of unfavourable factors. It was difficult to find a school that was "healthy" and had developmental potential. In the light of these realities, the confrontation with an ambitious vision of the school was a grotesque activity for the staff. In the strategy of these schools, it was first of all necessary to launch any development processes that would teach the staff how to set and implement objectives, build a sense of responsibility, and strengthen their belief that it is possible to achieve changes. This is an example of goals that should be set by an "ambitious" strategy for these centres and such goals should include an equally ambitious vision. For this reason, work on designing a strategy should begin with a diagnosis of the situation and not with a vision or mission. This approach is indicated, among others, by the aforementioned Rumelt.

\section{Strategy development process during moderated sessions}

The preparation of the strategy should start with work on the diagnosis of the situation. The basic questions to be answered are: what are we here for, what are we dealing with, what do they affect, what do we want? Rumelt calls this one statement - what is going on here?

In the methodology proposed here, however, there is a stage preceding the diagnosis, i.e. the stage of determining the criteria to be taken into account in the analysis of the situation. Starting the activities from defining the criteria allows to avoid the error of overlooking an important area of the organization's functioning during the diagnostic work.

Figure 1. The process of creating a strategy during a strategic session

Development criteria
Situation

diagnosis
Challenge/

/objective 
The diagnosis phase of the situation is firstly to allow to identify the factors determining the development and creation of problems in the organization, and secondly, to determine the causal and effect relationships between them. The result of the situation diagnosis is the preparation of a system of connections between the most important factors and the definition of "leverage", i.e. such a factor or factors that are particularly important for the development of the organisation.

After completing the diagnosis phase, the team is supposed to initially define what the goal which it wants to achieve is and the challenge it will have to face. Determining the goal requires an answer to the question "what do you want to achieve?

The next step is to identify the key challenge that needs to be taken in order to achieve the set goals. The challenge is the answer to the question "What is the main obstacle to achieving the goal?"The right challenge is the factor in a strategy that creates a breakthrough that drives the whole project. The implementation of a challenge often has a significant impact on the implementation of other elements of the strategy.

The stages described above were analytical in nature. They divided the general phenomena into the first factors. Creating a vision has a different character. It is an activity that synthesizes thinking. Vision is an idea of the final result of actions. Visualization of the desired effect which the team strives to achieve. Building a common vision of the future situation has a particular benefit. The way the team thinks about the organization becomes common, which leads to the same direction of thinking. A team that has a common idea of what it wants to achieve understands one another better and cooperates more effectively.

The preparation of the strategy concept is a stage in which the team works on the issue of developing the way to achieve the vision and goals. It identifies obstacles, tasks, factors that should be taken into account when implementing the objectives. It then organizes them into a coherent system and creates an action plan.

The discussed process (diagnosis-objectives/challenge-vision-concept) is a process of mutual feedback. These stages influence one another. The preparation of the strategy concept may give the team a new reference framework and show the situation in a different light, which in turn may 
result in the need to verify the diagnosis by taking into account the factors not taken into account so far. This, of course, may influence the shape of the vision and change the concept of strategic actions. This process ends when the team concludes that all its elements are considered to be coherent and complementary.

\section{Methods used in the strategy session}

In the next part of the article we will present selected methods used at particular stages of the strategy development process.

The basic methods that are used during the session are about 20 . The choice of them depends first of all on the stage, secondly on the specificity of the problem that the team is working on, and thirdly also on the specificity of the group - for example, working with officials uses fewer creative methods, and more analytical methods that more correspond to the specificity of work and thinking of this professional group.

\section{Kawakita Relation Diagram - Meta Method}

Before the individual stages of the strategy design process and the methods used in the work on a given stage are discussed here, it is first necessary to present a superior method to all the others - the Kawakita relatedness diagram (Corejowa, Borkowski, 2004, p. 32-35). It can be described as a meta-method, because it can be used at every stage of work on solving team problems, as a tool supporting other methods. In particular, it is useful when working on diagnosing a problem, when searching for solutions and when identifying the factors conditioning (limiting and supporting) the implementation of solutions. The aim is to identify and order a large number of factors. Working with the Kawakita diagram consists of the following steps:

- assigning cards to team members

- writing ideas

- categorising ideas

- selection of the best ideas 
The team working on solving the problem must equip themselves with small cards (fiches). These cards are used to write down ideas. Each team member working on the problem has to write down as many ideas as possible, but the basic rule is to write one idea per card. Writing down ideas in this way gives every team member the opportunity to express their opinion, because there is no possibility for the leader to dominate the group or for those team members who have a low level of assertiveness to break through with their ideas. Writing down also guarantees that no ideas will be lost during further stages of work. After the generation of ideas is completed, the next step is to organize the information. The team has to organize the cards, making them into groups of the same thematic categories. The work with the diagram ends when the team has put all the ideas in order. The next step, i.e. the selection of specific ideas, will be the result of the methods described later in the article.

\section{Development criteria}

The strategic session starts with the definition of the criteria determining the organization development. The team's task is to answer the question: which areas should be taken into account during the session in order to prepare a strategy? The aim of this stage is to prepare the team for further work and to direct it to the right path of thinking about development. One of the problems when working with teams is to direct the thinking of individual team members in such a way that they look at their organisation from the perspective of the whole and not only from the point of view of their own department. Already at this stage of the work, an outline of the structure of terms to be used later in the session is created.

The most frequently mentioned areas that determine development include: budget, staff competences, quality of cooperation and communication in the organisation, the quality of products/services, marketing, internal procedures, relations with the environment. In the case of ASP, these were: cooperation with the environment, cooperation of the staff, image of the university brand, quality of education, scientific/artistic development. 
Although there are specific methods that can help the team to identify important areas, due to the initial, preparatory nature of work and usually the need to save time, the method used here is a list of factors. In the course of the discussion, the team should select about 10 areas and prioritise them. When creating this ranking, no particular accuracy is required in the selection of the order. The most important is to build awareness of the existence of these areas.

\section{Diagnosis of the situation}

The next stage of the strategy building process is the situation diagnosis. The team is confronted with the question - which existing factors hinder the development of the organization, and which ones support it? As a starting point, the team is to refer to the criteria defined in the previous stage and, based on this, determine specific factors or phenomena in terms of their significance for development. Examples of such phenomena within the criterion of cooperation between team members may be: a) a general good climate of cooperation between departments in the company - as a positive aspect, and b) a conflict between two key experts, which the organic effectiveness of implemented projects - as negative. There is no limit to the number of factors taken into account. Each member of the team is able to identify any number of positive and negative factors in each criterion. If the team determines that there are additional factors beyond the scope of the aforementioned criteria, it is fully entitled to take them into account.

The is a high probability that a team consisting of several dozen members will generate at this stage several dozen or even more than 100 factors influencing the organization development. Further work on such a large number of components could not be effective or even possible without the support of organizing and selecting methods. Therefore, in the next step it is necessary to organize the factors according to the Kawakita Affinity Diagram.

Regardless of how much in the initial phase of the work was identified by a set of factors, 20-40 of them ultimately remain in 6-8 basic categories after being ordered and selected. This is the right moment for the team to make a visual presentation of the situation on the Ishikawa diagram (Robinson, 2005, pp. 74-79). 
The Ishikawa Diagram is a popular tool in the area of quality work (TQM). Specialists often associate it with the area of improving the quality of production and the quality of procedures. However, this diagram also works well in the analysis of an organisation. An example of a completed Ishikawa diagram is shown in Fig. 1. The diagram is structured as follows: the main problem that the team is working on is marked on the main axis. The side axes indicate the factors within each category. The number of axes corresponds to the number of categories prepared by the assembly. When working on a diagram, it is important that the team does not create too many categories. Experience shows that the maximum number of categories (i.e. side axes) should not exceed eight. Excessive information is created above and the diagram becomes illegible. In the example given below, the most important factors influencing the development of ASP are taken into account.

The use of the Ishikawa diagram allows to look at all the key factors from a perspective and in an orderly manner. While preparing the diagram in one of large Polish corporations, the participants said that for the first time since the beginning of the company's existence, all the most important issues discussed by the managers in the corridors were presented in the diagram.

In the analysed example, the ASP team consisting of the rector, vice-rectors, deans and vice-deans during the work on the strategy identified several dozen potential factors determining the development of the University. In the course of further selection, he identified more than 20 most significant of them. At this stage of work, it is still difficult to deduce which factors may be crucial for the purposes of further strategy preparation. It is significant, however, that a significant number of factors identified by the team is arranged according to clear categories, which allows for a detailed assessment of the significance of each of them. Without listing these factors and using the ordering method, it is not possible to continue effective teamwork. Each member of the team has a different understanding of the situation in which the organisation finds itself and most often, when proposing solutions, takes into account the conditions that are closest to his or her heart.

The next step in the process of diagnosing the situation is to create links between factors. The aim of this measure is to show causal and effect relations between factors and to identify those of them which are of particular importance and are crucial for the development of the entire organisational system. Examples of creating links between factors are shown in the Figure 3. 
Figure 2. Example of an Ishikawa diagram application for ASP.

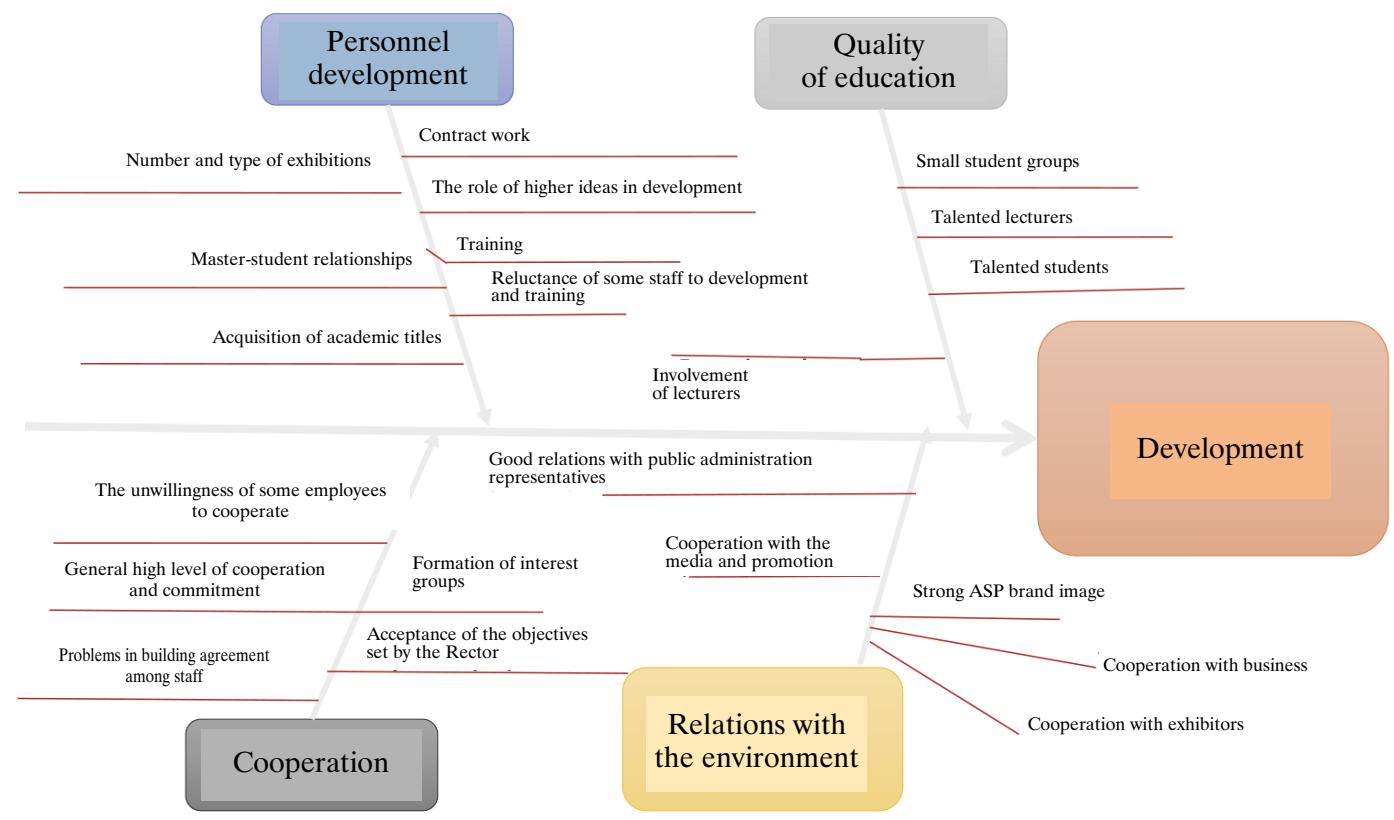

Source: Own elaboration based on training materials.

During the work on building links between factors in the ASP team, the image of key factors influencing the development of the university started to crystallize. Two main areas requiring development were identified. The factor related to the environment was the image of the University's brand and the need to strengthen it. The implementation of this objective was to help encourage talented candidates to join the Academy of Fine Arts, and at the same time build relations with business and city authorities. The second key area was the improvement of cooperation quality among the ASP staff. Thanks to the implementation of this objective, the efficiency of tasks and the effectiveness of scientific development were to be improved. 
Figure 3. Links between factors

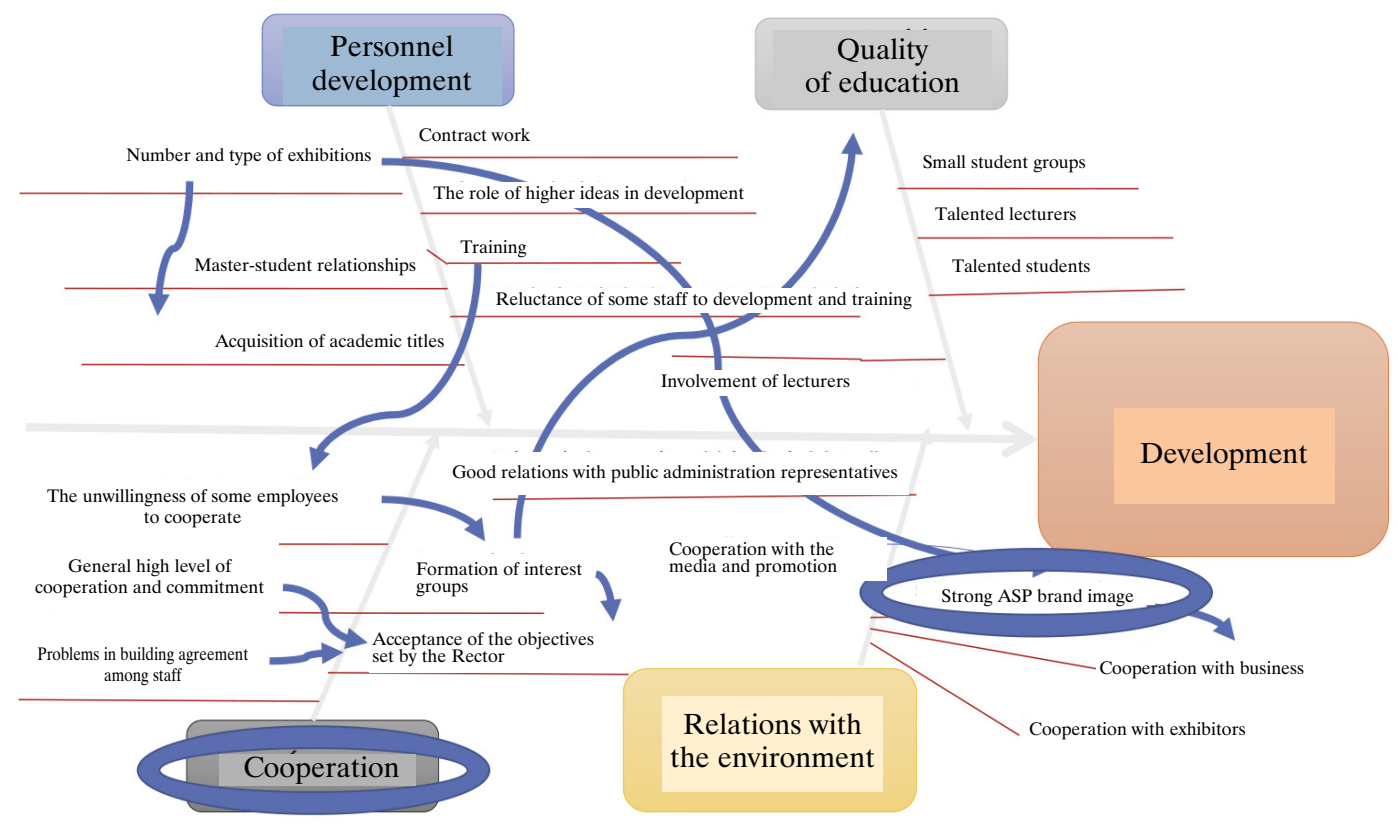

Source: Own elaboration based on training materials.

\section{ASP Objectives and Challenge}

After the diagnosis of the situation, the next step is to define the objectives. Targets should result directly from the diagnosis, but do not have to be the same as those described in the Ishikawa diagram. Based on the diagnosis, the team is to decide whether the goals it considers to be the most important result from the factors on which the team has worked so far, or whether it wants to set completely new goals. In the case of the session at the Academy of Fine Arts, the team defined 4 strategic goals:

- Building a strong image of the Academy of Fine Arts in its surroundings 
- Improving the quality of education (university-wide approach to curricula)

- Internationalisation of the higher education institution

- Development of external cooperation.

Building a strong image of the University in its environment was connected with reaching the awareness of the city's inhabitants, local authorities and businesses. Thanks to this action, the mission of the University was realized, but it was also to help build contacts beneficial for the development of the University, staff and students. To achieve this goal, it is necessary to be present more intensively in events such as events, exhibitions, vernissages, and also by intensifying cooperation with the media.

The improvement of the quality of education was mainly related to the improvement of curricula and cooperation between teachers. A problem at many universities is the improvement of curricula when subjects are to be taught by lecturers from different faculties. Due to the fact that lecturers belong to other organisational units of universities and have less possibility of contact with each other, and often also have a different understanding of the needs and specificity of other faculties functioning, subjects taught in cooperation with faculties can be inconsistent with each other. To achieve this goal, it was necessary to put emphasis on communication and cooperation of the teaching staff.

Internationalisation of the University was associated with greater openness to foreign students, cooperation with foreign universities, galleries and business. The development of external cooperation concerned enterprises that would be interested not only in commercialization of projects created by students and employees of the Academy of Fine Arts, but also in their employment.

Challenge is a different concept from purpose, however, in some situations purpose and challenge may overlap. The challenge addresses a key problem, an obstacle that hinders or even prevents the achievement of the objectives set. In the case of ASP, the main challenge was to achieve stronger integration and closer cooperation between University staff. The existence of problems in communication, 
insufficient support in the implementation of projects by team members and the formation of subgroups made it difficult to implement practically every goal set during the session because each of them required agreement and joint work. This problem was noticed and considered significant both for the Rector of the University and the rest of the management staff. Improvement of communication and relations was considered a priority action.

\section{Vision of the University}

A vision is the most general and desirable image of the situation that management would like to bring its organisation to. Going beyond rationality and common sense - to some extent - can be an added value in its formulation. The function of the vision is on the one hand to define the superior direction of the organization's development and on the other hand to motivate the team to work hard. Based on the conclusions obtained in the diagnostic part, the ASP team formulated the following vision:

"ASP as the best university in Poland, significant in the world. Our lecturers set the most important directions in art and design. We and our continuators are an opinion-forming force shaping the environment and the world. We nurture the values of mutual respect, the need for development, student support and commitment in many dimensions.

Spectacular projects and undertakings are constantly and enthusiastically implemented which increase our huge output. Our graduates are in demand on the global labour market, increase the economic growth of the whole Europe, shape the sensitivity and attitudes of the recipients of their work all over the world".

Evaluating the content of the vision after a few weeks of cooling off , the team started to question the two aspects mentioned here. The first one concerned the impact of the ASP on economic growth. The relationship between project design and student education and economic indicators was discussed. In the opinion of some of the staff, these unions were too distant from each other and therefore unreliable. Suggestions were made that this aspect should be removed from the vision. 
The second, a much more controversial aspect, was setting directions in art and design by the Academy's lecturers. The discussion concerned the issue of whether the aim of the Academy of Fine Arts is to create trends. The differences of opinion among the staff were significant and the discussion divided them into two camps. The problem was not solved, but this aspect was to remain part of the vision.

Eventually, the team decided that the realization of such a vision remains within the scope of the University's ability to achieve, all the more so because most of it is already being realized.

Building the concept of strategy is an activity whose aim is to give structure to the tasks, the implementation of which is to allow to achieve the goals set at an earlier stage. This stage is to answer the question what should be taken into account when implementing the objectives? The most important stages and tasks should be defined here, as well as obstacles which condition the achievement of particular strategic objectives. They then need to be organised into a single concept and prioritised. During the process of setting up the tasks, it may turn out that the actions for the implementation of one objective are convergent and, in any case, support the actions for the implementation of another objective. This creates a synergy effect, which is very desirable and supports the strategy implementation. At the same time, the opposite may also happen when it turns out that the implementation of one of the objectives will hamper work on another objective, e.g. by absorbing resources or contradictory logic. An example of such actions may be building openness of communication among the staff while expecting secrecy regarding the projects implemented by the departments. In such a situation, it may turn out that the previously set goals require revision. This process should be repeated as long as the team does not achieve coherence in the system of diagnosis-objectives-strategy.

Implementation. The objectives that were set by the ASP management team did not have an internal contradiction and to a large extent supported each other. Building the brand image even required the development of cooperation with external organisations - these objectives were linked by strong synergistic dependencies. At the same time, the improvement of the quality of education or 
internationalisation of activities was also conducive to brand building.

There would be no justification for presenting specific measures to achieve specific objectives. This is the operational level of the organisation's activity, which was largely developed outside the strategic session as part of the work of subassemblies.

A much more important issue was to face the challenge perceived by the staff - the improvement of cooperation between employees, both in the horizontal system and in hierarchical relations. Achieving the success of this challenge was to be a breakthrough action that enabled, or at least significantly accelerated, the implementation of all the set objectives. For this reason, a programme of development and staff integration was launched at the university. It was addressed primarily to the management staff. It was attended by rectors, deans and chairmen. It was conducted by an external company which conducted specialist trainings and coaching for individual persons from the staff. Initially, it was treated with mistrust, as it was the first training for the University's management staff in history. Finally, the programme was accepted with great enthusiasm, and at the request of the staff, the next edition of the programme was carried out. Most of the management staff took an active part in it.

\section{Summary}

The aim of the article was to present the methodology of building the organization's strategy applying the methodology used during moderated strategic sessions. The case of the Academy of Fine Arts in Łódź, where the author of the article conducted strategic sessions in 2017, was used to explain the different stages and the specificity of the methods. The basic process of building a strategy is based on the following stages: diagnosis of the situation, defining the challenge and vision, preparing and then evaluating solutions and planning implementation activities. The article describes selected methods used at particular stages of the process, except for the stage of planning activities. It results from the fact that during the session the teams expect the moderator to carry them out through the process from the 
diagnosis of the situation to the definition of new directions of development (solutions), and leave the work on detailed, operational planning for working meetings. This part is time consuming and much less creative, so the teams during the session prefer to work on areas that they cannot deal with as effectively as they can with the help of a moderator.

The methodology presented in the article is universal, i.e. it does not depend on the industry or the size of the organization. It is equally suitable for building a company's strategy as well as a charity association. The methods described here are not innovative in themselves. They are mostly known and described in the literature. The value here, however, is the way in which these methods are ordered - that is, the session methodology, as well as the interpretation of the meaning and role of individual methods in the process of building a strategy.

\section{References}

${ }^{1}$ An example of another tool that is perfect for visualizing an organizational situation is Buzan's Mind Map.

\section{Bibliography}

1. Corejowa T., Borkowski S., (2004). Instrumenty rozwiąywania problemów w zarzadzaniu. Sosnowiec: ABAKO.

2. GUS (2017), Szkoty wyższe.

3. Kłeczek R., Kowal W, Woźniczka J. (2001). Strategiczne planowanie marketingowe. Warszawa: PWE.

4. Martyniak Z. (1999). Metody organizacji i zarzązania. Kraków: Wydawnictwo Akademii Ekonomicznej w Krakowie.

5. Mikosik P. (2014). Problemy zarzadzania marketingowego niepubliczna szkoła wyższą. MINiB 3 (13).

6. PWN, 2018. https://sjp.pwn.pl/sjp/facylitacja;2557384.html (dostęp 17.09.2018)

7. Robinson M, (2005). Grupowe rozwiazywanie problemów. Warszawa: PWE.

8. Rumelt R., (2013) Dobra strategia, zła strategia. Czym się różnią i jakie to ma znaczenie. Warszawa: MT Biznes.

9. Schuman H. (2013). Metoda i znaczenie $w$ badaniach sondażowych. Warszawa: Oficyna Naukowa.

10. Wright P., Pringle D., Kroll J. M., (1992). Strategic management, Text and cases. Boston: Allyn and Bacon. 
Piotr Mikosik, PhD, Warsaw Management University, Poland — academic teacher with 18 years of experience, he deals with strategic management and employee development. He gained business experience as, among others, a consultant in the international consulting company IMPAC SYSTEMS and as a member of the management of an IT company - Intercon. Moreover, he is a management coach and he holds the certificate of ICC (International Coaching Community). He has trained, among others, the management of KGHM, Bank Spółdzielczy in Skierniewice, Telewizja Polska, representatives of public administration in Warmia-Mazury voivodeship, of the management of the Academy of Fine Arts in Łódź. 